\title{
腾格里沙漠人工固沙植被演替过程中生物土壤结 皮归一化植被指数的变化特征
}

赵 芸 1,2 贾荣亮 ${ }^{*}$ 高艳红 ${ }^{1}$ 周媛媛 ${ }^{1,2}$ 滕嘉玲 1,2

${ }^{1}$ 中国科学院西北生态环境资源研究院沙坡头沙漠研究试验站, 兰州 $730000 ;{ }^{2}$ 中国科学院大学, 北京 100049

摘 要 生物土壤结皮(简称结皮)影响干旱沙区生态系统归一化植被指数(NDVI)。该文基于空间代时间的方法, 利用地物光 谱仪采集腾格里沙漠不同始植年代(1956、1964和1973年)固沙植被区发育的5种优势结皮的NDVI数据, 分析了固沙植被演替 过程中结皮 NDVI的变化特征及其对降水和温度变化的响应规律, 并通过与固沙区主要地物进行比较, 评估了结皮NDVI在该 沙区生态系统NDVI中的作用。结果表明: 1)随着固沙植被演替, 结皮 $N D V I$ 逐渐增加。不同种类结皮 $N D V I$ 相比较, 土生对齿藓 (Didymodon vinealis)结皮>真藓(Bryum argenteum) 结皮>混生结皮>地衣结皮>藻结皮。2)结皮NDVI受降水量、气温及二者间的 交互作用影响显著, 且具有明显的季节差异。结皮 NDVI与降水量及其覆盖土壤浅层含水量均呈显著线性正相关关系, 并且结 皮NDVI对水分的敏感性随固沙植被演替而逐渐增加。结皮NDVI总体与日平均气温呈显著线性负相关关系, 而与结皮表面温 度呈显著指数负相关关系, 并且结皮 $N D V I$ 对温度的敏感性随固沙植被演替逐渐增加。结皮 NDVI对温度变化的敏感性春季高 于夏季，对水分变化的敏感性夏季高于春季。3)春季降水后，藓类结皮 NDVI显著高于油蒿(Artemisia ordosica)、花棒 (Hedysarum scoparium)、柠条(Caragana korshinskii)等灌木及裸沙; 夏季降水后, 结皮NDVI显著低于灌木。若考虑结皮较高的 盖度, 春、夏季结皮 NDVI对固沙区系统NDVI的贡献率分别为 $90.01 \%$ 和 $82.53 \%$, 均超过灌木(春季 $9.99 \%$ 和夏季 $17.47 \%$ ), 并且 结皮对固沙区系统NDVI的贡献率随着固沙植被演替而逐渐增加, 而灌木的贡献率逐渐降低。该研究证明了在区域尺度上利 用结皮 NDVI并结合气象资料区分结皮演替阶段的可行性, 并为干旱沙区在区域尺度上地表生态参量遥感估算的误差分析及 结皮遥感监测的时相选择提供了数据基础。

关键词 归一化植被指数; 生物土壤结皮; 植被演替; 降水; 温度

引用格式: 赵芸, 贾荣亮, 高艳红, 周媛媛, 滕嘉玲 (2017). 腾格里沙漠人工固沙植被演替过程中生物土壤结皮归一化植被指数的变化特征. 植物生 态学报, 41, 972-984. doi: 10.17521/cjpe.2017.0105

\section{Characteristics of normalized difference vegetation index of biological soil crust during the succession process of artificial sand-fixing vegetation in the Tengger Desert, Northern China}

ZHAO Yun ${ }^{1,2}$, JIA Rong-Liang ${ }^{1 *}$, GAO Yan-Hong ${ }^{1}$, ZHOU Yuan-Yuan ${ }^{1,2}$, and TENG Jia-Ling ${ }^{1,2}$

${ }^{1}$ Shapotou Desert Research and Experiment Station, Northwest Institute of Eco-Environment and Resources, Chinese Academy of Sciences, Lanzhou 730000, China ; and ${ }^{2}$ University of Chinese Academy of Sciences, Beijing 100049, China

\begin{abstract}
Aims Biological soil crust (hereafter crust) affects normalized difference vegetation index (NDVI) values in arid desert ecosystems. This study aimed to demonstrate the feasibility of combining crust NDVI values with meteorological data to distinguish the crust successional stage at the regional scale. Meanwhile, the characteristics of crust NDVI could provide the basis for the error analysis of NDVI-based surface ecological parameters estimation in desert ecosystems. We also suggested the optimum periods for crust observation based on the multi-temporal remote sensing images.

Methods NDVI values of five types of dominant crusts, three typical sand-fixing shrubs and bare sand were collected by spectrometer in the field. Crusts and shrubs were randomly selected in revegetated areas established in 1956, 1964, and 1973 at Shapotou, which is on the southeastern edge of the Tengger Desert. We used the space-for-time method to study the characteristics of crust NDVI values and their responses to precipitation and temperature during the succession process of artificial sand-fixing vegetation. Additionally, we evaluated the contribution of crust $N D V I$ values to the whole ecosystem $N D V I$ values by comparing the NDVI values of crusts, shrubs and bare sand.
\end{abstract}

收稿日期Received: 2017-04-21 接受日期Accepted: 2017-07-09

* 通信作者Author for correspondence (E-mail: rongliangjia@163.com) 
Important findings 1) With succession process of the artificial sand-fixing vegetation, the crust NDVI values significantly increased. Among different crust types, we found the following order of NDVI values: Didymodon vinealis crust $>$ Bryum argenteum crust $>$ mixed crust $>$ lichen crust $>$ algae crust. 2) Crust NDVI values were significantly affected by precipitation, temperature and their interaction, and the influences showed significant seasonal differences. Furthermore, we found significantly linear correlations between crust NDVI value and precipitation, and between crust NDVI value and the shallow soil moisture content covered by crust. A significantly negative linear correlation between daily mean temperature and crust $N D V I$ value, and a significantly exponential correlation between the surface temperature of crust and its NDVI value. With the succession process of artificial sand-fixing vegetation, the response of crust NDVI value to precipitation and temperature became more sensitive. In addition, the response of crust $N D V I$ value to temperature was more sensitive in spring than in summer, while that to precipitation was less sensitive in spring than in summer. 3) Moss crust NDVI value was significantly higher than that of shrubs and bare sand after the rainfall event in spring, while shrubs NDVI value was significantly higher than that of crust after the rainfall event in summer. Considering the coverage weights of different ground features in sand-fixing areas, crust $N D V I$ values contributed $90.01 \%$ and $82.53 \%$ in spring and summer, respectively, to the regional NDVI values, which were higher than those of shrubs $(9.99 \%$ and $17.47 \%$ in spring and in summer, respectively). Additionally, with the succession process of artificial sand-fixing vegetation, crust $N D V I$ values contributed more, while shrubs contributed less to regional NDVI values.

Key words normalized difference vegetation index; biological soil crust; vegetation succession; precipitation; temperature

Citation: Zhao Y, Jia RL, Gao YH, Zhou YY, Teng JL (2017). Characteristics of normalized difference vegetation index of biological soil crust during the succession process of artificial sand-fixing vegetation in the Tengger Desert, Northern China. Chinese Journal of Plant Ecology, 41, 972-984. doi: 10.17521/cjpe.2017.0105

生物土壤结皮(简称结皮)是干旱沙区重要的地 表生物覆盖物, 在沙区土壤生态、水文和地球化学 循环等过程中发挥着重要作用, 其发育及演替特征 常被作为重要指标来衡量生态系统稳定性和健康程 度(李新荣等, 2009, 2014; 李新荣, 2010)。因此, 在 区域尺度上，结皮的时空动态对于沙区生态系统管 理具有重要的参考价值(李新荣等, 2014; Weber \& Hill, 2016)。虽然基于实验室测量或地块试验, 针对 结皮的空间分布特点(张元明等, 2004; Maestre et al., 2005; 李新荣等, 2016)、拓殖和演替规律(Kleiner, 1983; Eldridge \& Tozer, 1997; Zaady \& Bouskila, 2002; Dettweiler-Robinson et al., 2013; 李新荣等, 2016)和碳储量估算(贾荣亮, 2009; Grote et al., 2010; 冯薇, 2014)等已有较多报道, 但由于结皮生物自身 变水特性且易受到植被、土壤和地形等因素的影响, 其时空分异明显(王雪芹等, 2006; 程军回和张元明, 2010; 赵允格等, 2010), 使得上述研究结果往往难 以准确推广到区域尺度。而遥感技术在较大尺度研 究方面具有明显的技术优势, 为大尺度结皮时空格 局监测、评估其碳储量、固碳/氮潜力和其他生态功 能提供了重要机遇(Weber \& Hill, 2016)。

遥感应用研究的重要依据、遥感数据解译及定 量分析的基础是地物光谱特征(赵英时等, 2003)。地
物光谱特征是指地物对太阳辐射的吸收、反射及透 射随波长的变化特征。不同地物类型由于其结构及 所处地表环境的差异而具有各自的光谱特征，同类 地物表现为光谱相似性特点。这也是能够利用遥感 信息识别不同地物的根本原因(赵英时等, 2003)。归 一化植被指数 (NDVI) 作为表征植被生长速率及植被 覆盖度的最佳指示因子, 常用于植被覆盖动态分析 及各类模型进行叶面积指数、叶绿素含量、净初级 生产量 (NPP) 等植被生态参数估算 (赵英时等, 2003; Pettorelli et al., 2005)。

自20世纪90年代开始, 国内外一些学者基于对 结皮光谱特征的分析研究建立了在遥感影像上提取 结皮覆盖度的结皮指数(Karnieli, 1997; Chen et al., 2005; Weber et al., 2008; Rozenstein \& Karnieli, 2014), 其中有学者认为结合NDVI和结皮指数能够 提高结皮覆盖度的提取精度(Rozenstein \& Karnieli， 2014; 冯秀线等, 2015)。也有学者尝试利用 NDVI在 遥感影像上区分结皮与维管植物(Karnieli, 2003)。但 是, 同样由于结皮生物的变水特性及其有别于维管 植物的物候节律造成其 NDVI的水分变异性和季节 变异性(Karnieli et al., 1996; Karnieli, 2003; Fang et al., 2015)较大, 而且不同演替阶段结皮在形态结构 和光合生理特征方面差异较大(Zaady et al., 2000; 
徐杰等, 2005; Housman et al., 2006; 贾荣亮, 2009; 苏延桂等, 2010; 王媛等, 2014; Zhang \& Zhang; 2014), 且其分布随地形变化差异较大(王雪芹等, 2006; 程军回和张元明, 2010; 赵允格等, 2010), 引 起干旱半干旱地区 $N D V I$ 的不稳定性, 增加了遥感 图像解译的困难而降低了以 NDVI为基本参量进行 植被生态参数的遥感估算准确性和精度(Karnieli et al., 1996; 房世波和张新时, 2011; Fang et al., 2015; Rodriguez- Caballero et al., 2015)。

虽然已有少量研究证实了不同演替阶段、不同 类型结皮的光谱特征存在差异, 并认为依托光谱分 析能够识别结皮的种类组成和演替阶段(Zaady et al., 2007; Ustin et al., 2009; Chamizo et al., 2012), 但是, 这些研究涉及结皮种类较少, 特别是缺乏同种类型 结皮不同演替阶段的差异比较。因此, 本研究通过 分析腾格里沙漠人工固沙植被演替过程中不同演替 阶段结皮 $N D V I$ 的变化特征及其对降水和温度变化 的响应规律，探讨不同演替阶段不同类型、同种类 型不同演替序列结皮NDVI在沙区生态系统中的贡 献率及其演变特征, 为结皮演替遥感研究提供重要 参数基础, 也为这一地区结皮遥感解译影像的时相 选择提供重要参考。

\section{1 材料和方法}

\section{1 研究区概况}

本试验在中国科学院沙坡头沙漠研究试验站包 兰铁路北侧的人工固沙植被区内 $\left(37.45^{\circ} \mathrm{N}, 104.95^{\circ} \mathrm{E}\right.$, 海拔1 $330 \mathrm{~m}$ )进行。该区年平均气温 $10.0{ }^{\circ} \mathrm{C}$, 低温极 值 $-25.1{ }^{\circ} \mathrm{C}$, 高温极值 $38.1{ }^{\circ} \mathrm{C}$, 年降水量 $186.2 \mathrm{~mm}$ (1956-2012年), $80 \%$ 的降水集中在5-9月, 5-7月的平 均温度为 $24{ }^{\circ} \mathrm{C}$, 年潜在蒸发量 $3000 \mathrm{~mm}$, 主风向为 西北风, 年平均风速 $2.9 \mathrm{~m} \cdot \mathrm{s}^{-1}$, 属于温带荒漠化草 原向草原化荒漠的过渡区。该区主要的景观类型是 高大密集的格状新型沙丘链, 沙丘由西北向东南倾 斜, 呈阶梯状分布, 沙丘间零星散布有沙蓬(Agriophyllum squarrosum)、百花蒿(Stilpnolepis centiflora) 等一年生草本植物(Li et al., 2014)。

为防治包兰铁路沙坡头地区路基的风沙危害, 确保铁路安全运行, 自1956年起在铁路南北两侧建 立了人工植被生态防护体系, 之后在不同年代 (1964年、1973年、1981年等)又逐步扩建。经过半 个多世纪的演替, 体系内植被、土壤发生深刻演变,
主要固沙植被有柠条(Caragana korshinskii)、油蒿 (Artemisia ordosica)和花棒(Hedysarum scoparium) 等。结皮也逐渐形成并发育成为地表的主要覆盖物, 最高盖度在 $90 \%$ 以上(Jia et al., 2008; 李新荣, 2010)。定居其间的结皮生物种类丰富, 主要有具鞘 微鞘藻 (Microcoleus vaginatus)、双尖菱板藻 (Hantzschia amphioxys)、隐头舟形藻 (Navicula cryptocephala)等藻类和真藓(Bryum argenteum)、土 生对齿蘚(Didymodon vinealis)、齿肋赤藓(Syntrichia caninervis)等藓类及球胶衣(Collema cocophorum)、 石果衣(Endocarpon pusillum)、鳞网衣(Psora decipiens)等地衣(李新荣, 2010)。藓类结皮广泛分布在 迎风坡和丘间低地，地衣结皮分布在丘顶，藻结皮 分布以阳坡居多，混生结皮则在各地貌部位皆有分 布, 结皮常随水分差异、发育阶段、季节变化而呈 现不同的颜色。

\section{2 样方设置}

本试验于2015年4-8月进行。利用空间取样代替 时间的方法，选取1956年、1964年和1973年的植被 固沙区和裸沙作为研究样地, 分别代表该区固沙植 被的 4 个演替阶段(固沙植被建立 $59 、 51 、 42$ 和 0 年), 同时也代表结皮的不同演替序列。为了评估人工固 沙植被演替过程中结皮NDVI值大小, 试验分别设 置了结皮观测样方和灌木观测样方(一年生草本植 物的盖度随降水的年际变化较大, 因此试验未设置 草本植物样方)。样方设置具体步骤为: 首先沿这3 个演替阶段植被区, 随机设置3条平行样带, 样带间 隔超过 $20 \mathrm{~m}$, 每条样带延伸至附近流沙区各 1 个裸 沙样方 $(1 \mathrm{~m} \times 1 \mathrm{~m})$; 然后沿每条样带, 在各演替阶 段的植被区迎风坡随机设置 $10 \mathrm{~m} \times 10 \mathrm{~m}$ 的大样方; 最后根据样方内结皮类型、灌木种分别设置结皮、 灌木长期固定观测小样方, 重复 3 个(灌木株数小于 3 个的按实际株数设置)。

为消除维管植物对结皮 NDVI的影响, 每种结 皮小样方 $(1 \mathrm{~m} \times 1 \mathrm{~m})$ 布设在随机选择的维管植物群 落斑块中间的开阔地段, 样方内结皮盖度超过 98\%。柠条、油蒿和花棒灌木小样方根据冠幅大小 设置, 为避免灌木下结皮对灌木 NDVI的干扰, 观测 时在灌木下平铺面积大于冠幅的黑布。

\section{3 结皮和灌木盖度、NDVI测定方法}

参照李新荣等(2000)和李新荣(2010)的方法分 别调查样方内灌木的总盖度和分盖度及结皮的总盖 
度和分盖度。使用主动遥感光谱仪 GreenSeeker (Trimble, Sunnyvale, USA)采集地物NDVI数据, 该 仪器通过自身携带的高强度发光二极管发出红光和 近红外光, 接收器测定其发射回传感器的光, 并通 过一个电子滤波器消除所有的背景光, 由系统自带 软件分别以NIR $((780 \pm 6) \mathrm{nm})$ 和R $((671 \pm 6) \mathrm{nm})$ 波段计算 $N D V I$ 值, 光谱仪视场大小为 $(60.96 \pm$ $10.16) \mathrm{cm} \times(1.52 \pm 0.50) \mathrm{cm}$, 出厂前已经对仪器进 行了校正。测量时使仪器传感器探头与灌木冠层、生 物结皮、裸沙表面平行并保持同一垂直高度 $(0.8 \mathrm{~m})$, 每次测量在样方不同位置, 以10次测量求取的平均 值为该小样方地物的 $N D V I$ 值, 每个重复小样方的 测量值再平均作为大样方内该类型结皮、灌木种和 裸沙的NDVI值。降水量对结皮 NDVI值影响较大, 本 研究将观测前 10 日内无降水时的观测值为干结皮 $N D V I$ 值, 在降雨结束后的当日或者隔日的观测值为 湿结皮 $N D V I$ 值。

使用土壤水分仪(TDR300, Spectrum Technologies, Plainfield, USA)同步测定各个样方0-7.6 cm土 层土壤体积含水量, 测量结束后用原土壤填补 TDR 探针插入时留下的空隙。干旱(观测前10天内无降水) 时, 土壤水分含量少, 为了便于比较, 采用烘干法测 得质量含水量并换算为体积含水量。同时使用红外温 度测量仪(Minolta/Land Cyclops Compac 3, Land, Sheffield, England)测量样方内结皮表面温度, 温度测量 保证在尽量短的时间内完成, 以忽略太阳辐射变化 对生物结皮表面温度的影响。试验期间主要的气象因 子(降水和空气温度)由距离研究区 $50 \mathrm{~m}$ 左右的自动 气象站(Milos 520, Vaisala, Helsinki, Finland)观测。

\section{4 数据分析}

采用Origin 8.5 进行数据处理与绘图, 利用 SPSS 21.0中单因素方差分析法分析不同类型结皮 $N D V I$ 的差异显著性, 显著性检验采用最小显著差 异法(LSD); 应用线性回归的方法分析结皮NDVI随 固沙植被演替年龄的变化趋势; 应用线性及指数型 函数分别建立结皮NDVI随降水量, 其覆盖土壤浅 层含水量、气温及其表面温度的变化趋势, 根据回 归方程的变化速率(线性函数斜率及指数型函数一 阶导数)分析结皮NDVI对水分及温度变化的敏感性 随固沙植被演替的变化趋势。应用逐步回归分析结 皮 NDVI与降水量、气温、结皮覆盖土壤浅层含水量、 结皮表面温度的关系, 找出影响结皮 NDVI的主要
因素。采用偏相关分析法分析结皮NDVI对水分和温 度敏感性的季节变化。其中, 气温为研究区的日平 均气温, 降水为观测前一日至观测时研究区的累积 降水量; NDVI、结皮覆盖土壤浅层含水量及结皮表 面温度为各样点数据。本研究中, 地物 NDVI数据均 为地物光谱仪采集反射光谱计算所得。

由于大尺度的光谱混合可以被认为是一种线性 混合(童庆禧等, 2006), 本研究中利用固沙区各地物 $N D V I$ 与其盖度权重的线性模型, 计算固沙植被每 个演替阶段内的比重 NDVI值。比重NDVI即为固沙 区地物 NDVI的加权求和, 各自相应的盖度为权重 系数。本文中结皮和灌木对固沙区系统NDVI贡献率 特指结皮和灌木的比重 NDVI分别对二者总 NDVI的 贡献, 即贡献率=灌木或结皮比重 $N D V I /$ (灌木比重 $N D V I+$ 结皮比重 $N D V I)$ 。

\section{2 结果}

\section{1 腾格里沙漠人工固沙植被演替过程中生物土 壤结皮NDVI的变化特征}

5 种结皮NDVI均随固沙植被演替逐渐增大, 且 湿结皮 NDVI 与固沙植被演替时间具有更高的相关 性 $(p<0.05)$ (图1, 图2)。同一年代固沙区不同类型 结皮NDVI相比, 藓类结皮>混生结皮>地衣结皮> 藻结皮, 其中土生对齿藓结皮 $N D V I$ 显著高于其他 类型结皮 $(p<0.05)$, 真藓结皮 $N D V I$ 显著高于地衣 结皮和藻结皮 $(p<0.05)$, 混生结皮 NDVI与地衣结 皮 NDVI差异不显著。在 1965 年固沙区混生结皮 $N D V I$ 与真蘚结皮 $N D V I$ 差异显著 $(p<0.05)$, 而在 1964年及1973年固沙区两者差异不显著。此外, 干 湿结皮差异显著 $(p<0.05)$ (图2)。

\section{2 腾格里沙漠人工固沙植被演替过程中生物土 壤结皮NDVI对降水和温度的响应}

结皮NDVI受降水量、气温及两者间的交互作用 影响显著且具有明显的季节差异 $(p<0.05)$ (表 1 , 表 $2)$ 。结皮 $N D V I$ 与降水量及其覆盖土壤浅层含水量均 呈显著线性正相关关系 $(p<0.01)$, 并且结皮 $N D V I$ 对水分的敏感性随固沙植被演替而逐渐增加(图3)。 结皮 $N D V I$ 总体与日平均气温呈显著线性负相关关 系 $(p<0.05)$ 而与结皮表面温度呈显著指数负相关关 系 $(p<0.05)$, 并且结皮NDVI对温度的敏感性随固 沙植被演替逐渐增加(图4)。结皮 NDVI对温度变化的 敏感性春季高于夏季, 对水分变化的敏感性夏季高 


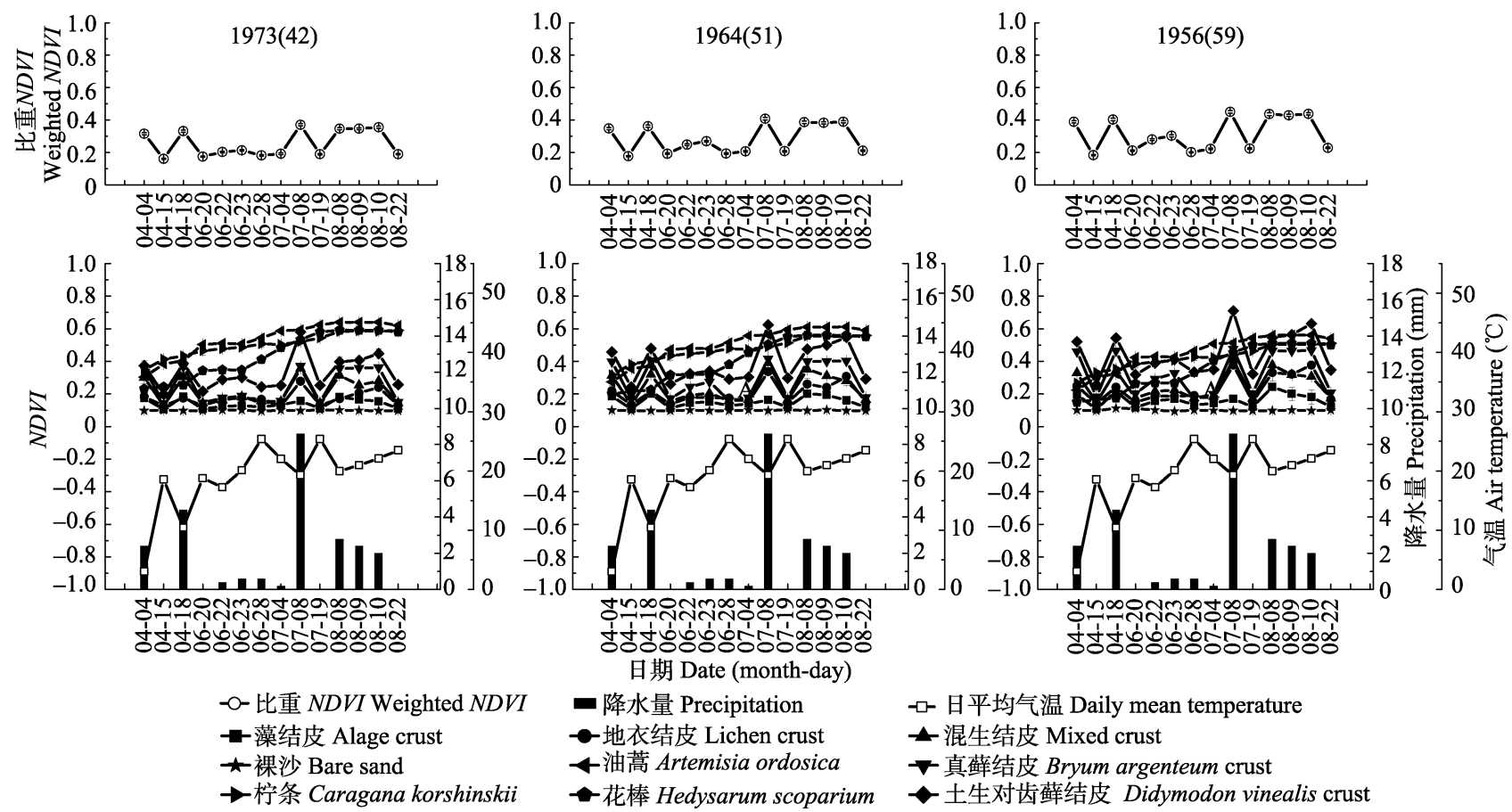

图1 腾格里沙漠人工固沙植被演替过程中不同地物归一化植被指数(NDVI)的季节变化。1973(42)、1964(51)、1956(59)表示 固沙植被建立年份(固沙年限(a))。

Fig. 1 Seasonal changes in normalized difference vegetation index (NDVI) values with the succession process of the artificial sand-fixing vegetation. 1973(42), 1964(51), 1956(59) represent year of revegetation (history of revegetation (a)).

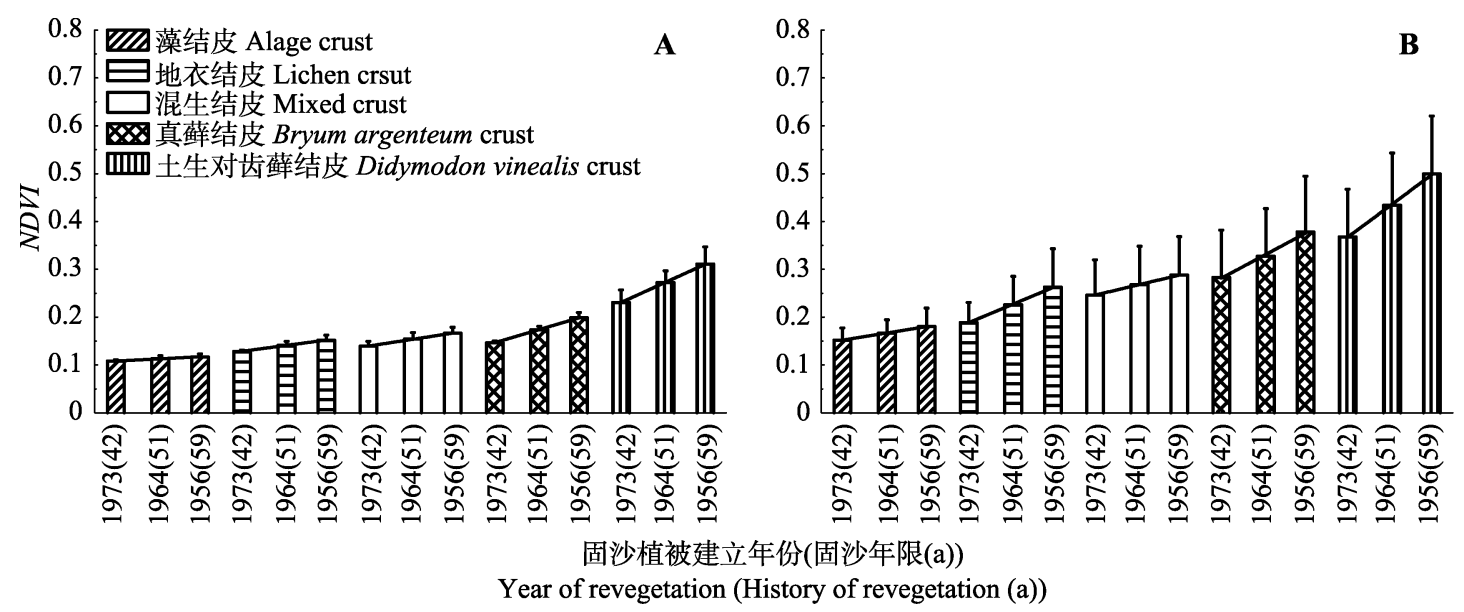

图2 腾格里沙漠人工固沙植被演替过程生物土壤结皮归一化植被指数 (NDVI) 的变化特征(平均值+标准偏差)。 $\mathrm{A}$, 干结皮。 B, 湿结皮。

Fig. 2 Changes in normalized difference vegetation index $(N D V I)$ values of biological soil crust with the succession process of artificial sand-fixing vegetation $($ mean $+S D)$. A, Dry crust. B, Wet crust.

表1 生物土壤结皮归一化植被指数(NDVI)与固沙植被演替年龄、降水量、气温、结皮表面温度及结皮覆盖土壤浅层含水量的逐步回归方程

Table 1 Stepwise regressions of the sand-fixing vegetation successional age, precipitation, daily mean temperature, surface temperature and shallow soil moisture content covered by biological soil crust with their normalized difference vegetation index $(N D V I)$ values

\begin{tabular}{llcc}
\hline 结皮类型 Crust type & 拟合方程 Fitted curves equation & $R^{2}$ & $p$ \\
\hline 藻结皮 Algae crust & $N D V I=0.146+0.006 P-0.002 S T+0.001 A-0.001 T$ & 0.494 & $<0.01$ \\
地衣结皮 Lichen crust & $N D V I=0.002+0.021 P+0.004 A+0.002 T-0.002 S T$ & 0.663 & $<0.01$ \\
混生结皮 Mixed crust & $N D V I=0.163+0.027 P-0.002 T+0.002 A-0.002 S T$ & 0.801 & $<0.01$ \\
真蘚结皮 Bryum argenteum crust & $N D V I=0.093+0.024 M+0.005 A-0.004 T+0.015 P-0.002 S T$ & 0.707 & $<0.01$ \\
土生对齿蘚结皮 Didymodon vinealis crust & $N D V I=-0.057+0.037 M+0.007 A+0.024 P$ & 0.819 & $<0.01$ \\
\hline
\end{tabular}

$A$, 固沙植被演替年龄; $M$, 结皮覆盖土壤浅层含水量; $P$, 降水量; $S T$, 结皮表面温度 $;$, 日平均气温。

$A$, sand-fixing vegetation successional age; $M$, shallow soil moisture content covered by biological soil crust; $P$, precipitation; $S T$, surface temperature of biological soil crust; $T$, daily mean temperature. 
表2 生物土壤结皮归一化植被指数 $(N D V I)$ 与水分及温度的偏相关系数 季节变化

Table 2 The partial correlation coefficient of normalized difference vegetation index (NDVI) values of biological soil crust in spring and summer

\begin{tabular}{lcc}
\hline & $\begin{array}{c}\text { 春季 } \\
\text { Spring }\end{array}$ & $\begin{array}{c}\text { 夏季 } \\
\text { Summer }\end{array}$ \\
\hline 结皮表面温度 Crust surface temperature & $-0.269^{* *}$ & $-0.139^{* *}$ \\
土壤体积含水量 Soil volumetric moisture content & 0.146 & $0.473^{* *}$ \\
日平均气温 Daily mean temperature & $-0.321^{* *}$ & -0.069 \\
降水量 Precipitation & $0.388^{* *}$ & $0.629^{* *}$ \\
\hline
\end{tabular}

**表示回归显著水平 $p<0.01$ 。

** represent significant level $p<0.01$.

于春季(表2), 逐步回归分析表明结皮覆盖土壤浅层 含水量是影响藓类结皮 $N D V I$ 的最关键因子，降水是 影响藻、地衣和混生结皮 $N D V I$ 的最关键因子(表1)。

2.3 腾格里沙漠人工固沙植被演替过程中生物土 壤结皮及灌木对固沙区系统NDVI的贡献率

春季降水后，藓类结皮 $N D V I$ 显著高于油蒿、花
棒、柠条等灌木及裸沙 $(p<0.05)$; 夏季降水后，结皮 $N D V I$ 显著低于灌木 $(p<0.05)$ 。若考虑结皮较高的盖 度, 春、夏季结皮 $N D V I$ 对固沙区系统 NDVI的贡献率 分别为 $(90.01 \pm 2.16) \%$ 和 $(82.53 \pm 3.17) \%$, 均超过灌木 $((9.99 \pm 2.16) \%$ 和 $(17.47 \pm 3.17) \%)$, 并且结皮对固沙 区系统 NDVI的贡献率随着固沙植被演替逐渐增加, 而灌木的贡献率则逐渐降低(图5)。

\section{3 讨论}

\section{1 腾格里沙漠人工固沙植被演替过程中生物土 壤结皮NDVI的变化特征}

伴随着腾格里沙漠人工固沙植被半个多世纪 的演替, 结皮在固沙区地表逐渐形成、发育和演变。 结皮演替过程体现在两个方面: 一是不同类型结皮 代表着结皮演替的不同阶段，按照演替过程中隐花
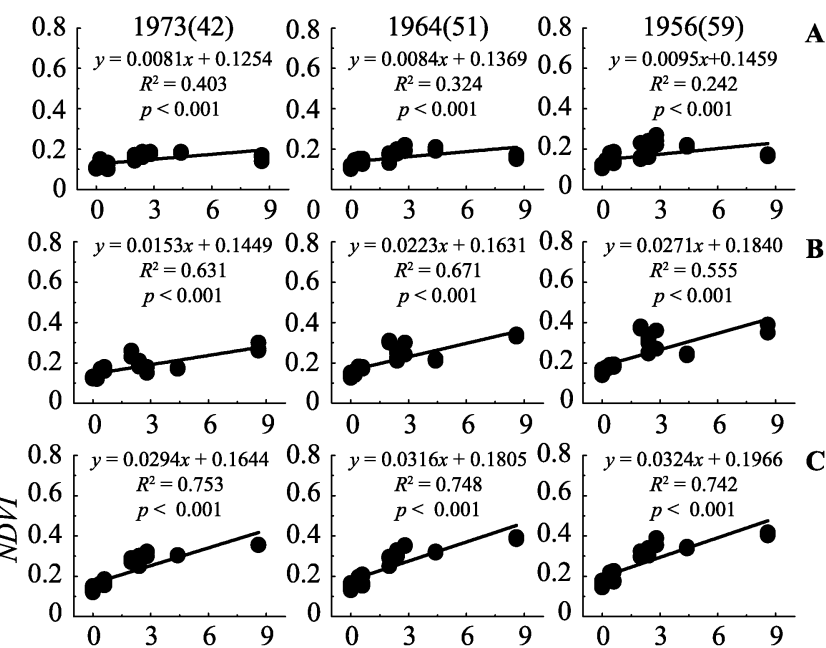

$0.8 f^{y=0.0343 x+0.1843} 0.8\left[^{y=0.0356 x+0.2214} 0.8\left[_{R^{2}=0.0408 x+0.2559}^{y=0.571}\right.\right.$ D
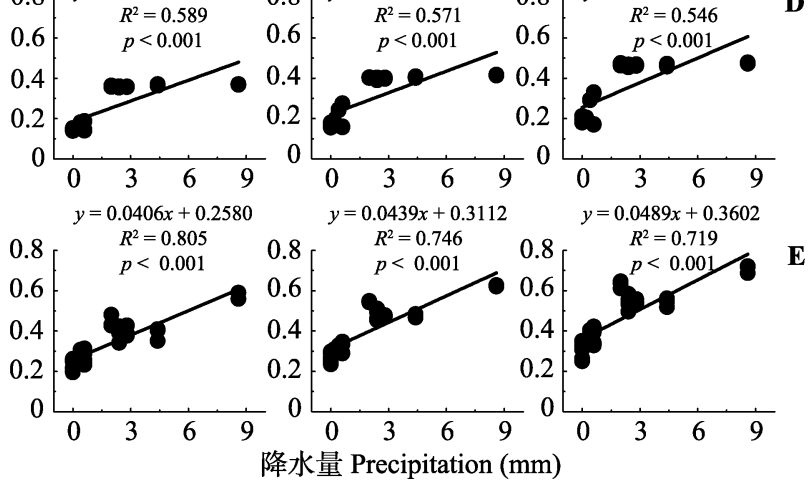

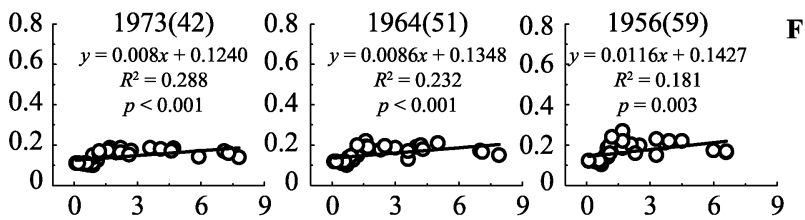

$0.8\left[\begin{array}{lll}y=0.0186 x+0.1358 & 0.8[y=0.0294 x+0.1498 & 0.8[y=0.0414 x+0.1614 \quad \text { G }\end{array}\right.$
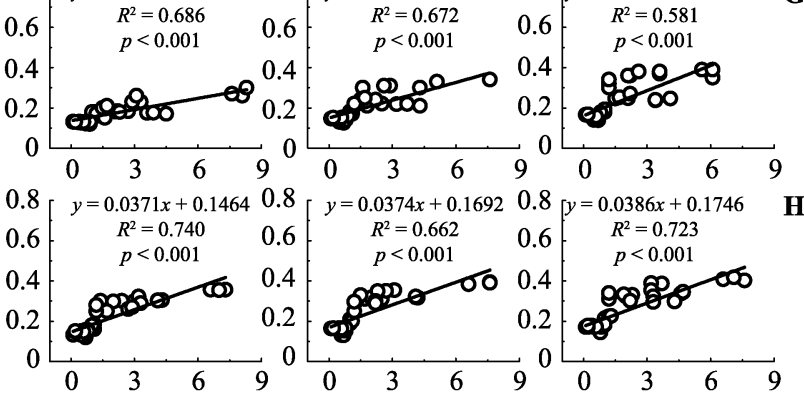

$0.8\left[\begin{array}{c}y=0.0400 x+0.1586 \\ R^{2}=0.553\end{array} 0.8\left[\begin{array}{ccc}y=0.0473 x+0.1867 & 0.8 \\ R^{2}=0.578 & y=0.0675 x+0.1856 \\ R^{2}=0.672 & \text { I }\end{array}\right.\right.$
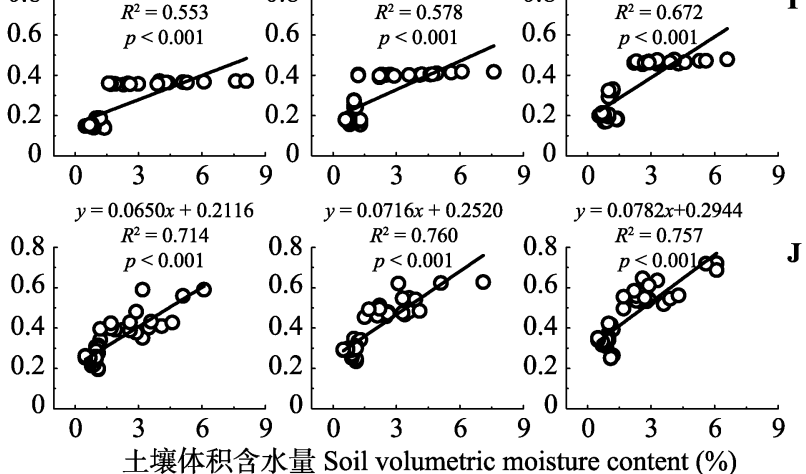

图3 腾格里沙漠人工固沙植被演替过程中生物土壤结皮归一化植被指数 (NDVI)对水分的响应。 $\mathrm{A}, \mathbf{F}$, 藻结皮。 $\mathbf{B}, \mathbf{G}$, 地衣结 皮。C, H, 混生结皮。D, I 真蘚结皮。E, J 土生对齿藓结皮。降水量为观测前一日至观测时的累积降水量。1973(42)、1964(51)、 1956(59)表示固沙植被建立年份(固沙年限(a))。

Fig. 3 Responses of normalized difference vegetation index (NDVI) values of biological soil crust to precipitation and shallow soil moisture content covered by biological soil crust during the succession process of artificial sand-fixing vegetation. A, F, Algae crust. B, G, Lichen crust. C, H, Mixed crust. D, I, Bryum argenteum crust. E, J, Didymodon vinealis crust. Precipitation means the cumulative precipitation during the previous 24 hours before the observation time. 1973(42), 1964(51), 1956(59) represent year of revegetation (history of revegetation (a)). 

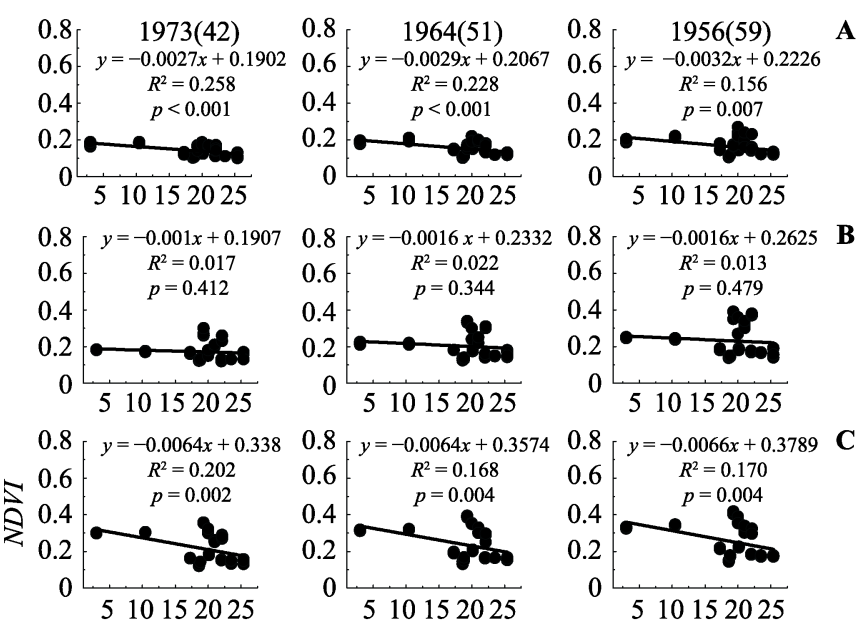

$0.8, y=-0.0086 x+0.4078$

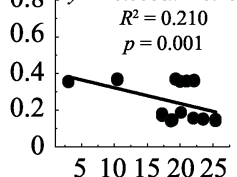

$y=-0.0044 x+0.4130$

$0.8\left[R^{2}=0.035\right.$

$0.6 \quad p=0.121$

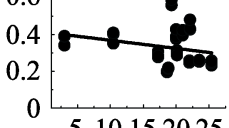

510152025

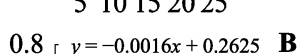

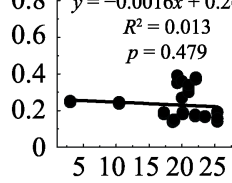

$0.8[y=-0.0066 x+0.3789 \mathrm{C}$
$0.8, y=-0.0093 x+0.46080 .8, y=-0.0109 x+0.5338$ D
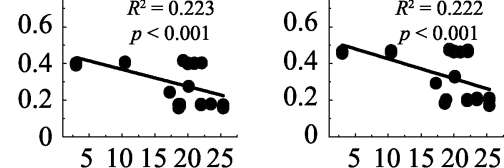

$y=-0.0060 x+0.5029$

510152025

$0.8\left[R^{2}=0.064\right.$

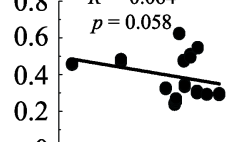

0.2

510152025

$y=-0.0068 x+0.5750$
$0.8 \quad R^{2}=0.062$

$\mathbf{E}$

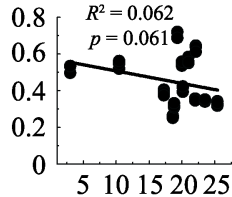

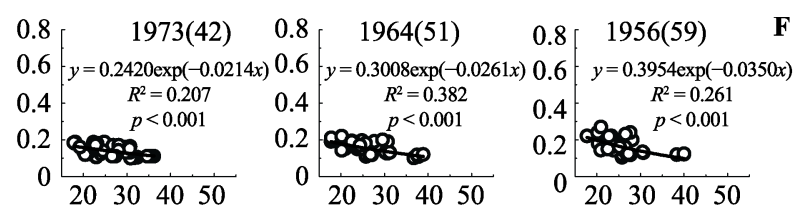

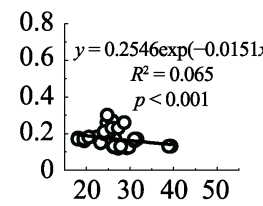

0.8 0.8 $\quad 0.8$

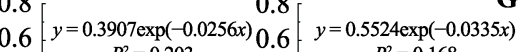

0.4 की $p<0.001$

0.2

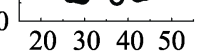

0.4 \& $\begin{aligned} & R^{2}=0.168 \\ & p<0.001\end{aligned}$

0.2 के

$\begin{array}{lllll}20 & 30 & 40 & 50\end{array}$
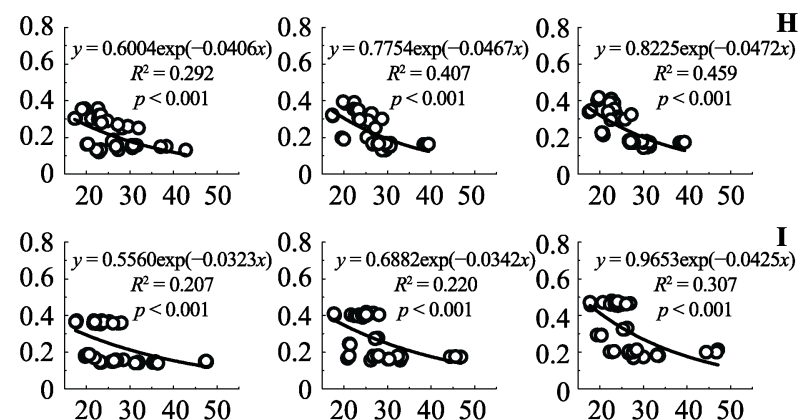

x) 0.8 0.6 $\left[\begin{array}{c}y=0.9653 \exp (-0.0425 x) \\ R^{2}=0.307\end{array}\right.$

0.4 erso $p<0.001$

0.4 o

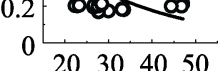

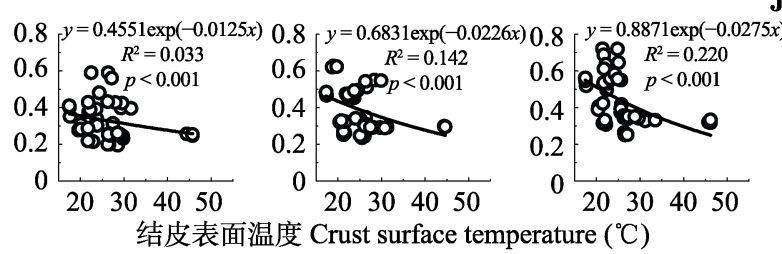

图4 腾格里沙漠人工固沙植被演替过程中生物土壤结皮归一化植被指数 $(N D V I)$ 对温度的响应。 $\mathbf{A}, \mathbf{F}$, 藻结皮。 $\mathbf{B}, \mathbf{G}$, 地衣结 皮。C, H, 混生结皮。D, I 真藓结皮。E, J 土生对齿藓结皮。1973(42)、1964(51)、1956(59)表示固沙植被建立年份(固沙年 限(a))。

Fig. 4 Responses of normalized difference vegetation index (NDVI) values of biological soil crust to daily mean temperature and surface temperature during the succession process of artificial sand-fixing vegetation. A, F, Algae crust. B, G, Lichen crust. C, H, Mixed crust. D, I, Bryum argenteum crust. E, J, Didymodon vinealis crust. 1973(42), 1964(51), 1956(59) represent year of revegetation (history of revegetation (a)).

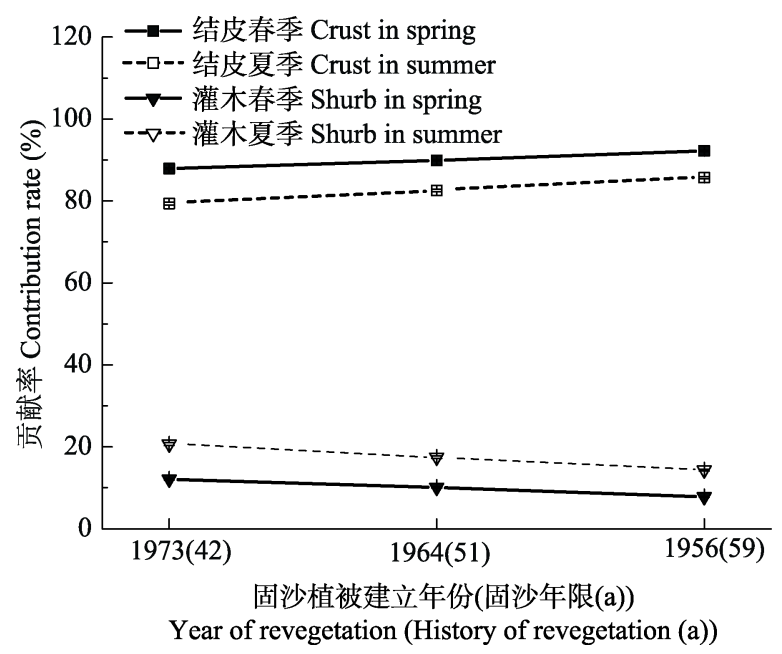

图5＼cjkstart腾格里沙漠人工固沙植被演替过程中生物土壤结皮及 灌木对固沙区系统归一化植被指数 (NDVI) 的贡献率。

Fig. 5 Changes in the contribution rate of normalized difference vegetation index (NDVI) values of biological soil crust and shrubs to the regional NDVI of sand-fixing system with the succession process of artificial sand-fixing vegetation.
植物替代的特点, 可分为演替早期的藻结皮阶段及 演替后期的地衣结皮、藓类结皮及混生结皮阶段(李 新荣, 2010), 本研究选择了演替由早及晚的藻结 皮、地衣结皮、混生结皮、真藓结皮及土生对齿藓 结皮。二是同一类型结皮的不同演替序列，本研究 中不同年代的固沙植被区代表了结皮的不同演替序 列。腾格里沙漠人工固沙植被区发育时间较长(1956 年固沙区)的湿润土生对齿藓结皮和藻结皮的NDVI 最高分别达到 0.71 和 0.24 , 明显高于植被建立前的 裸沙(图1)。而在以色列地区的研究表明湿润藓类结 皮和藻结皮 $N D V I$ 分别为 0.30 和 0.22 (Karnieli et al., 1996，1999), 即使在降水量较高的鄂尔多斯地区 (Fang et al., 2015)及毛乌素沙地(冯秀线等, 2015), 其夏季湿润藓类结皮NDVI也仅分别为 0.66 和 0.25 。 这可能与不同地区结皮的优势种、当地气候条件和 本研究区遭受干扰较少有关, 并反映了结皮伴随着 
固沙植被演替发育越来越好的发展趋势。

与维管植物相比, 在水分充足时, 结皮在较低 的温度和较弱的光照条件下也能进行光合作用而生 长(Lange et al., 1998; Lange, 2003)。本研究表明, 春 季降水后, 藓类结皮 $N D V I$ 显著高于油蒿、花棒和柠 条等灌木(图1), 若考虑各不同地物在固沙区的盖 度权重时, 结皮对固沙区系统NDVI的贡献高达 (90.01 \pm 2.16$) \%$ (图5)。Schmidt和Karnieli (2002)在以 色列地区的研究中也得出, 与高等植物相比较, 结 皮对早春NDVI峰值贡献最大。Fang等(2015)在鄂尔 多斯地区的研究表明, 夏季湿润藓类结皮的 NDVI (0.66)低于油蒿 $(0.74)$ 。本研究发现, 夏季降水较高 时湿润藓类结皮 $N D V I$ 显著低于油蒿(图1), 但与柠 条和花棒相近(图1)。并且结皮对固沙区系统 NDVI 的贡献((82.53 \pm 3.17$) \%)$ 仍高于灌木 $(17.47 \pm 3.17) \%)$ (图5)。随着固沙植被演替, 结皮对固沙区系统NDVI 的贡献率逐渐增加, 而灌木的贡献率逐渐降低(图 5)。这与固沙植被及结皮的演替过程密切相关。固 沙灌木幼苗的多度与浅层土壤含水量关系密切, 随 着固沙植被建立时间的延长, 灌木群落生物量呈现 降低趋势(冯丽等, 2009; Li et al., 2014)。而伴随固沙 植被演替, 结皮总盖度逐渐增加, 其中藻结皮在结 皮总盖度中所占的比例逐渐减小, 地衣结皮、藓类 结皮和混生结皮则逐渐增加。真藓结皮在藓类结皮 总盖度中所占的比例逐渐减小而土生对齿藓结皮则 逐渐增加(赵芸等, 2017)。本研究还发现, 固沙植被 建立50年后, 灌木的贡献率降低趋势不明显(图5), 这可能与结皮层的蚂蚁筑穴等生物活动在一定程度 上增加了深层土壤含水量的补给有关(Li et al., 2011)。 这说明 $N D V I$ 可以作为重要指标指示固沙植被及结 皮的演替变化, 从而表明干旱沙区植被建设可以依 靠较高的结皮贡献率来维持系统较高的 NDVI。

已有研究表明, 结皮 $N D V I$ 的高低受到其光合 色素含量和光合组织器官结构的共同影响(Dody et al., 2011; Fischer et al., 2012; Weber \& Hill, 2016), 而结皮演替过程中不同类型结皮在形态结构和光合 生理特征方面差异较大(Zaady et al., 2000; 田桂泉 等, 2005; 徐杰等, 2005; Housman et al., 2006; 贾荣 亮, 2009; 苏延桂等, 2010; 王雪芹等, 2011; 王媛等, 2014; Zhang \& Zhang; 2014)。首先, 从外表看, 藻结 皮薄而脆, 表面平滑; 地衣结皮则较粗粘, 表面常 有褶皱突起; 藓类结皮表现为藓类植物密集丛生
特征(王雪芹等, 2011), 并且不同种类藓结皮存在 差异: 土生对齿藓结皮高度和粗䊁度均高于真藓 结皮(贾荣亮, 2009)。其次, 比较叶细胞结构发现, 土生对齿藓厚且多疮而真藓叶细胞壁薄且平滑(田 桂泉等, 2005)。再者, 比较不同类型结皮叶绿素含 量发现, 藓类结皮叶绿素含量高于地衣和藻结皮 (Lange, 2003), 藓类结皮植株体集中了几乎全部的 光合色素, 地衣结皮叶状体集中了大部分的叶绿 素a, 而藻结皮叶绿素a多集中在与其紧密胶结的 土壤层(吴丽, 2012)。也有研究表明, 结皮粗粞度和 高度(徐杰等, 2005; Jia et al., 2008; 王媛等, 2014), 生物量(Li et al., 2003; 徐杰等, 2005)、叶绿素含 量、光合速率、PSII光化学效率等随结皮发育时间 的增加而增加(Zaady et al., 2000; Housman et al., 2006; 苏延桂等, 2010; 李新荣, 2010; Zhang \& Zhang; 2014)。上述这些变化导致不同类型结皮 $N D V I$ 差异 较大, 本研究结果也证实了这一点, 随着固沙植被 的演替, 结皮NDVI逐渐增加(图2)。Zaady等(2007) 在以色列地区研究了结皮遭受刮擦干扰后持续恢复 6年的 NDVI变化特征, 也发现结皮 $N D V I$ 与其演替时 间呈显著正相关, 并且这种相关性在雨季比旱季更 高, 这可能与结皮演替过程中其隐花植物的组成变 化相关。Dody等(2011)在同一地区的研究也认为 $N D V I$ 是指示结皮生长速率的良好指标。

此外, 本研究也发现, 随着固沙植被演替, 同 一类型结皮 $N D V I$ 逐渐增加, 并且湿润结皮 $N D V I$ 与 演替时间具有更高的相关性(图2)。逐步回归的结果 也显示, 固沙植被演替年龄是影响结皮NDVI的主 要因素(表1), 这表明 $N D V I$ 这一指标对于结皮演替 研究的潜力和重要性。这在一定程度上弥补了目前 国内外结皮NDVI研究方面多侧重于不同类型结皮 NDVI变化特征, 而对同一类型不同演替序列结皮 NDVI变化特征研究较少的不足。

\section{2 腾格里沙漠人工固沙植被演替过程中生物土 壤结皮NDVI对水分和温度的响应特征}

结皮生物种如藻、地衣、藓类等隐花植物都具 有变水特征, 生理活性对水分变化极度敏感。与维 管植物相比, 结皮生物在干燥复水后能迅速恢复光 合作用，而且很少的水分即能刺激结皮进行光合作 用(Lange, 2003; 李新荣, 2010)。尽管结皮生物对水 分的需求远远低于维管植物, 但其覆盖土壤表土层 的湿度对其存在和发展起着十分重要的作用(李新 
荣等, 2016)。Grote等(2010)的研究结果表明, 在新 墨西哥沙漠(热漠)中蓝藻结皮的净光合速率随着土 壤含水量的增加而增加, 沙漠中发育晚期的结皮在 中等土壤含水量的情况下达到最大净光合速率，而 犹他地区(凉漠)中早期结皮对土壤水分的变化相对 不敏感。本研究发现, 结皮 NDVI与其覆盖土壤浅层 含水量显著正相关(图3)。Karnieli等(1996)在以色列 地区的研究认为, 结皮水化后 NDVI的增加可能与 物质的移动和叶绿素的合成相关。本研究作者也认 为, 结皮水化后, 一方面加深了结皮光谱的叶绿素 吸收特征, 另一方面也改变了结皮细胞结构及形态 结构, 如真藓结皮被水湿润时, 配子体呈鲜绿色, 体积增大, 脱水时叶细胞壁变薄, 配子体变为暗绿 色(李新荣等, 2016), 形态结构差异引起地表反射率 的变化。本研究还发现, 降水前后结皮NDVI差异随 降水量的增加而增大: 当降水量不足 $1 \mathrm{~mm}$ 时, 降水 前后干、湿结皮 $N D V I$ 平均差值为 0.04 ; 当降水量为 2-5 mm时, 降水前后干、湿结皮 $N D V I$ 平均变化为 0.16 ; 当降水量为 $8.6 \mathrm{~mm}$ 时, 干湿结皮 $N D V I$ 平均变 化0.21 (图1); 而且不同演替阶段相比, 处于演替后 期的藓类结皮降水前后 NDVI的变化最大, 而处于 演替早期的藻结皮变化最小(图1)。

比较不同类型结皮 NDVI与降水量及其覆盖土 壤浅层含水量的相关性发现, 结皮NDVI对水分的 敏感性随着结皮演替逐渐增加: 土生对齿藓结皮 $>$ 真藓结皮>混生结皮>地衣结皮>藻结皮(图3)。逐步 回归的结果也表明, 结皮覆盖土壤浅层含水量是影 响藓类结皮NDVI的最关键因子, 而降水是影响藻 结皮、地衣结皮及混生结皮NDVI的最关键因子(表 1)。究其成因, 可能与不同演替阶段结皮生理活性 对水分的利用效率和对水分的需求存在差异有关, 比较而言, 藓类结皮光合作用的水分补偿点和饱和 点高于地衣结皮和藻结皮(李新荣, 2010), 藓类结皮 还具有更高的持水能力, 能够维持更长的湿润时间 (Colesie et al., 2012), 而与真藓结皮相比, 土生对齿 藓结皮具有更高的饱和吸水率(徐杰等, 2005)。比较 同一类型不同演替序列结皮也发现相同的变化趋势 (图3), 这是因为结皮的发育厚度、对干旱的耐受能 力及饱和吸水量等随着固沙年限的增加而增加(徐 杰等, 2005; 李守中等, 2008)。

尽管结皮植物对温度的适应范围较广, 但低温 和高温均不利于结皮隐花植物的生物量积累(李新
荣, 2010)。本研究发现结皮NDVI与日平均气温呈显 著线性负相关而与结皮表面温度显著指数负相关 (图4), 这可能与较低温度时结皮表面保持湿润的时 间延长而光合产物积累降低有关。并且结皮 NDVI 对温度的敏感性随固沙植被演替逐渐增加, 这表明 结皮的形成和发育逐渐改变了固沙区地表辐射过程, 并进一步影响土壤表层的热量收支(姚德良等, 2002)。Li等(2012)在同一地区的研究结果表明, 结 皮覆盖土壤表层含水量是结皮日固碳量高低的决定 性因素。本研究中逐步回归分析表明, 水分是影响 结皮 $N D V I$ 的最关键因子(表1), 但同时也受到气温 和结皮表面温度的影响, 这是因为温度条件不同时, 结皮的水分利用效率也将发生变化。而不同演替序 列结皮的地表辐射特性存在差异影响其表面温度, 进而影响其生理活性。结皮生理活性对温度和水分 的响应存在季节性变化。本研究发现, 从春季到夏 季, 结皮 NDVI对温度的敏感性降低, 对降水的敏感 性增加(表2)。这说明, 结皮的生理活性有耐低温的 特点, 但结皮叶绿素的合成和水分利用率仍然受到 温度的影响(李新荣, 2010), 因此春季结皮 $N D V I$ 并 不随降水量的显著增加而增加, 而在夏季其生理活 性随着降水量的增加而显著提高(表1)。Fang等(2015) 在鄂尔多斯地区的研究结果显示, 夏季干湿苔藓结 皮 $N D V I$ 差异大于秋季, 并认为结皮光谱在夏秋季 的差异与结皮的营养期(7月)及生殖期(9月)的差异 生长有关。本研究发现, 夏季干湿结皮的差异大于 春季。但是在腾格里沙漠沙坡头地区藓类植物常不 生孢子体, 主要是靠植物体碎片进行繁殖(白学良 等, 2003)。因此, 本研究认为, 结皮NDVI季节变化 与结皮隐花植物的植株体的季节生长及叶绿素含量 随降水的季节变化有关。

\section{3 腾格里沙漠人工固沙植被演替过程中生物土壤 结皮NDVI变化特征在沙区生态遥感应用中的意义}

结皮是干旱、半干旱沙区重要的地表生物覆盖 物, 其发育及演替特征常用于指示沙区生态系统稳 定和受损生态系统恢复程度(李新荣, 2010)。以往干 旱、半干旱地区应用 NDVI进行植被动态解译和生产 力估算研究时结皮的作用常被忽略。直到 20 世纪 90 年代起, 结皮对 NDVI稳定性的影响才逐渐受到重 视, 基于遥感技术的结皮覆盖度提取研究逐渐增加 (Karnieli et al., 1996, 1999)。本研究发现, 结皮NDVI 对固沙区系统NDVI的贡献率较高(图5), 这表明如 
果忽略结皮 NDVI在沙区生态遥感中的作用, 将增 加遥感估算的误差。

在技术应用方面，Fang等(2015)研究了夏秋季 节结皮光谱的差异, 并指出结皮光谱的季节差异可 以为结皮遥感解译中影像的时相选择提供依据, 但 并未给出具体的操作方法。本研究认为, 在春季维 管植物生长伊始(萌芽)时, 分析降水前后的高时间 分辨率影像能够提取结皮信息: NDVI变化较大的像 元可能对应有结皮覆盖, 降水后 $N D V I$ 较大 $(>0.25)$ 可能是由像元中藓类结皮覆盖比例较高或结皮的覆 盖比例较高引起, 但仍无法提取灌木下的结皮信息, 这也是目前存在的技术难题, 还需要进一步研究。 虽然传统生态学基于实验室对结皮生物理化性质的 分析进行结皮的演替研究最为可靠、准确, 但这种 方式破坏性大, 耗费人力物力, 且无法从大尺度评 估结皮演替变化(Chamizo et al., 2012)。本研究发现, 湿润结皮NDVI对其演替变化具有良好的指示能力 (表1), 且在夏季降水量 $>2.5 \mathrm{~mm}$ 时, 同一固沙区不 同类型结皮也差异显著(图1), 这表明利用湿润结皮 $N D V I$ 并结合气象资料在区域尺度上区分结皮演替 阶段的可行性。

以往绝大多数研究非常关注苔藓结皮盖度对其 覆盖区域短时间内 NDVI稳定性的影响, 但并未考 虑结皮的演替变化(房世波和张新时, 2011)和季节 生长(Karnieli et al., 1996; Rodriguez-Caballero et al., 2015)。由于干早沙区降水变率较大, 而不同类型结 皮分布随地形变化差异较大, 并且不同类型结皮及 同一类型不同演替序列结皮厚度存在差异，对降水 的拦截量不同，因此，即使在同一时间，结皮覆盖 土壤表土层水分状况也不同, 由此引起结皮 $N D V I$ 空间变异。本研究发现结皮NDVI随降水变化的波动 程度受到结皮总盖度、不同类型结皮及同一类型不 同演替时间序列结皮覆盖比例的影响, 结皮总盖度 中发育水平越高和发育时间越长的结皮的覆盖比例 越高, 区域NDVI随降水的波动越大, 并且夏季波动 程度大于春季(图1)。因此本研究认为, 在干旱沙区 利用植被指数进行生态遥感分析时, 应该对影像获 取前的气象资料尤其是降水资料予以重视, 结皮对 降水和气温的响应规律对于指导沙区植被遥感分析 具有重要意义。

基金项目 国家自然科学基金(41371099、41671210
和41530746)和中国科学院“西部之光”人才培养引 进计划。

致谢本实验得到中国科学院沙坡头沙漠研究试验 站的支持, 在此感谢。

\section{参考文献}

Bai XL, Wang Y, Xu J, Li XR, Zhang JG (2003). Characteristics of reproduction and growth of mosses in the soil crust of fixed dunes in Shapotou area. Journal of Desert Research, 23, 171-173. (in Chinese with English abstract) [白学良, 王瑶, 徐杰, 李新荣, 张景光 (2003). 沙坡头 地区固定沙丘结皮层藓类植物的繁殖和生长特性研究. 中国沙漠, 23, 171-173.]

Chamizo S, Stevens A, Cantón Y, Miralles I, Domingo F, van Wesemael B (2012). Discriminating soil crust type, development stage and degree of disturbance in semiarid environments from their spectral characteristics. European Journal of Soil Science, 63, 42-53.

Cheng HJ, Zhang YM (2010). Environmental factors affecting soil biocrust distribution. Chinese Journal of Ecology, 29, 133-141. (in Chinese with English abstract) [程军回, 张 元明 (2010). 影响生物土壤结皮分布的环境因子. 生态 学杂志, 29, 133-141.]

Chen J, Zhang MY, Wang L, Shimazaki H, Tamura M (2005). A new index for mapping lichen-dominated biological soil crusts in desert areas. Remote Sensing of Environment, 96, $165-175$.

Colesie C, Scheu S, Green TGA, Weber B, Wirth R, Büdel B (2012). The advantage of growing on moss: Facilitative effects on photosynthetic performance and growth in the cyanobacterial lichen Peltigera rufescens. Oecologia, 169, 599-607.

Dettweiler-Robinson E, Ponzetti JM, Bakker JD (2013). Long-term changes in biological soil crust cover and composition. Ecological Processes, 2, 1-10.

Dody A, Hakmon R, Asaf B, Zaady E (2011). Indices to monitor biological soil crust growth rate-Lab and field experiments. Natural Science, 3, 478-483.

Eldridge DJ, Tozer ME (1997). Environmental factors relating to the distribution of terricolous bryophytes and lichens in semi-arid eastern Australia. Bryologist, 100, 28-39.

Fang SB, Yu WG, Qi Y (2015). Spectra and vegetation index variations in moss soil crust in different seasons, and in wet and dry conditions. International Journal of Applied Earth Observation \& Geoinformation, 38, 261-266.

Fang SB, Zhang XS (2011). Impact of moss soil crust on vegetation indexes interpretation. Spectroscopy and Spectral Analysis, 31, 780-783. (in Chinese with English abstract) [房世波, 张新时 (2011). 苔藓结皮影响干旱半干旱植 被指数的稳定性. 光谱学与光谱分析, 31, 780-783.] 
Feng L, Zhang JG, Zhang ZS, Guo Q, Li XR (2009). Growth and biomass allocation dynamics of Artemisia ordosica in sand-fixing vegetation of the Tengger Desert of China. Journal of Plant Ecology (Chinese Version), 33, 11321139. (in Chinese with English abstract) [冯丽, 张景光, 张志山, 郭群, 李新荣 (2009). 腾格里沙漠人工固沙植 被中油蒿的生长及生物量分配动态. 植物生态学报, 33, 1132-1139.]

Feng W (2014). Photosynthetic Carbon Fixation of Biological Soil Crusts in $M u$ Us Desert and Their Impact on Soil Carbon Emission. PhD dissertation, Beijing Forestry University, Beijing. 61-73. (in Chinese with English abstract) [冯薇 (2014). 毛乌素沙地生物结皮光合固碳过程及对 土壤碳排放的影响. 博士学位论文, 北京林业大学, 北 京. 61-73.]

Feng XR, Bu CF, Hao HK, Yang YZ, Zhang GJ (2015). Research on biological soil crust extraction by spectral analysis in Mu Us Desert, China. Journal of Natural Resources, 30, 1024-1034. (in Chinese with English abstract) [冯秀 线, 卜崇峰, 郝红科, 杨延征, 张广军 (2015). 基于光 谱分析的生物结皮提取研究——毛乌素沙地为例. 自然资源学报, 30, 1024-1034.]

Fischer T, Veste M, Eisele A, Bens O, Spyra W, Hüttl RF (2012). Small scale spatial heterogeneity of normalized difference vegetation indices (NDVIs) and hot spots of photosynthesis in biological soil crusts. Flora, 207, 159167.

Grote EE, Belnap J, Housman DC, Sparks JP (2010). Carbon exchange in biological soil crust communities under differential temperatures and soil water contents: Implications for global change. Global Change Biology, 16, 27632774.

Housman DC, Powers HH, Collins AD, Belnap J (2006). Carbon and nitrogen fixation differ between successional stages of biological soil crusts in the Colorado Plateau and Chihuahuan Desert. Journal of Arid Environments, 66, 620-634.

Jia RL (2009). Photosynthetic Ecophysiological Characteristics of Moss Crusts in A Revegetated Area of the Tengger Desert, Northern China. PhD dissertation, Cold and Arid Regions Environmental and Engineering Research Institute, Chinese Academy of Sciences, Beijing. (in Chinese with English abstract) [贾荣亮 (2009). 腾格里沙漠人工植被 区藓类结皮光合生理生态学研究. 博士学位论文, 中国 科学院寒区旱区环境与工程研究所, 北京.]

Jia RL, Li XR, Liu LC, Gao YH, Li XJ (2008). Responses of biological soil crusts to sand burial in a revegetated area of the Tengger Desert, Northern China. Soil Biology \& Biochemistry, 40, 2827-2834.

Karnieli A (1997). Development and implementation of spectral crust index over dune sands. International Journal of Remote Sensing, 18, 1207-1220.
Karnieli A (2003). Natural vegetation phenology assessment by ground spectral measurements in two semi-arid environments. International Journal of Biometeorology, 47, 179187.

Karnieli A, Kidron GJ, Glaesser C, Ben-Dor E (1999). Spectral characteristics of cyanobacteria soil crust in semiarid environments. Remote Sensing of Environment, 69, 67-75.

Karnieli A, Shachak M, Tsoar H, Zaady E, Kaufman Y, Danin A, Porter W (1996) The effect of microphytes on the spectral reflectance of vegetation in semiarid regions. Remote Sensing of Environment, 57, 88-96.

Kleiner EF (1983). Successional trends in an ungrazed, arid grassland over a decade. Journal of Range Management, 36, 114-118.

Lange OL (2003). Photosynthesis of soil-crust biota as dependent on environmental factors. In: Belnap J, Lange OL eds. Biological Soil Crust: Structure, Function, and Management. Springer, Berlin. 217-240.

Lange OL, Belnap J, Reichenberger H (1998). Photosynthesis of the cyanobacterial soil-crust lichen Collema tenax from arid lands in southern Utah, USA: Role of water content on light and temperature responses of $\mathrm{CO}_{2}$ exchange. Functional Ecology, 12, 195-202.

Li SZ, Zheng HZ, Li SL, Shen BC (2008). Development characteristics of biotic crusts on Shapotou vegetated sand dunes. Chinese Journal of Ecology, 27, 1675-1679. (in Chinese with English abstract) [李守中, 郑怀舟, 李守丽, 沈宝成 (2008). 沙坡头植被固沙区生物结皮的发育特 征. 生态学杂志, 27, 1675-1679.]

Li XR (2010). Eco-hydrology of Biological Soil Crusts in Desert Regions of China. Higher Education Press, Beijing. (in Chinese) [李新荣 (2010). 荒漠生物土壤结皮生态与水 文学研究. 高等教育出版社, 北京.]

Li XR, Hui R, Zhao Y (2016). Eco-physiology of Biological Soil Crusts in Desert Regions of China. Higher Education Press, Beijing. (in Chinese) [李新荣, 回嵘, 赵洋 (2016). 中国荒漠生物土壤结皮生态生理学研究. 高等教育出 版社, 北京.]

Li XR, Jia RL, Chen YW, Huang L, Zhang P (2011). Association of ant nests with successional stages of biological soil crusts in the Tengger Desert, Northern China. Applied Soil Ecology, 47, 59-66.

Li XR, Zhang JG, Liu LC, Chen HS, Shi QH (2000). Plant diversity in the process of succession of artificial vegetation type sand environment in an arid desert region of china. Acta Phytoecologica Sinica, 24, 257-261. (in Chinese with English abstract) [李新荣, 张景光, 刘立超, 陈 怀顺, 石庆辉 (2000). 我国干旱沙漠地区人工植被与环 境演变过程中植物多样性的研究. 植物生态学报, 24 , 257-261.]

Li XR, Zhang P, Su YG, Jia RL (2012). Carbon fixation by biological soil crusts following revegetation of sand dunes

www.plant-ecology.com 
in arid desert regions of China: A four-year field study. Catena, 97, 119-126.

Li XR, Zhang YM, Zhao YG (2009). A study of biological soil crusts: Recent development trend and prospect. Advances in Earth Science, 24, 11-24. (in Chinese with English abstract) [李新荣, 张元明, 赵允格 (2009). 生物土壤结皮 研究: 进展、前沿与展望. 地球科学进展, 24, 11-24.]

Li XR, Zhang ZS, Tan HJ, Gao YH, Liu LC, Wang XP (2014). Ecological restoration and recovery in the wind-blown sand hazard areas of northern China: Relationship between soil water and carrying capacity for vegetation in the Tengger Desert. Science China Life Sciences, 57, 539-548.

Li XR, Zhao Y, Hui R, Su JQ, Gao YH (2014). Progress and trend of development of restoration ecology research in the arid regions of China. Progress in Geography, 33, 14351443. (in Chinese with English abstract) [李新荣, 赵洋, 回嵘, 苏洁琼, 高艳红 (2014). 中国干旱区恢复生态学 研究进展及趋势评述. 地理科学进展, 33, 1435-1443.]

Li XR, Zhou HY, Wang XP, Zhu YG, O'conner PJ (2003). The effects of sand stabilization and revegetation on cryptogam species diversity and soil fertility in the Tengger Desert, Northern China. Plant and Soil, 251, 237-245.

Maestre FT, Escudero A, Martinez I, Guerrero C, Rubio A (2005). Does spatial pattern matter to ecosystem functioning? Insights from biological soil crusts. Functional Ecology, 19, 566-573.

Pettorelli N, Vik JO, Mysterud A, Gaillard JM, Tucker CJ, Stenseth NC (2005). Using the satellite-derived NDVI to assess ecological responses to environmental change. Trends in Ecology \& Evolution, 20, 503-510.

Rodriguez-Caballero E, Knerr T, Weber B (2015). Importance of biocrusts in dryland monitoring using spectral indices. Remote Sensing of Environment, 170, 32-39.

Rozenstein O, Karnieli A (2014). Identification and characterization of biological soil crusts in a sand dune desert environment across Israel-Egypt border using LWIR emittance spectroscopy. Journal of Arid Environments, 112, 75-86.

Schmidt H, Karnieli A (2002). Analysis of the temporal and spatial vegetation patterns in a semi-arid environment observed by NOAA AVHRR imagery and spectral ground measurements. International Journal of Remote Sensing, 23, 3971-3990.

Su YG, Li XR, Chen YW, Zhang ZS (2010). Photosynthetic characteristic of algal crusts in the desert area. Journal of Lanzhou University: Natural Sciences, 46, 1-5. (in Chinese with English abstract) [苏延桂, 李新荣, 陈应武, 张 志山 (2010). 不同演替序列的藻结皮净光合速率日变 化特征. 兰州大学学报: 自然科学版, 46, 1-5.]

Tian GQ, Bai XL, Xu J, Zhang JS (2005). Morphological and structural properties as well as adaptation of mosses in microbiotic soil crusts on fixed dunes. Journal of Desert Research, 25, 249-255. (in Chinese with English abstract)
[田桂泉, 白学良, 徐杰, 张建升 (2005). 固定沙丘生物 结皮层藓类植物形态结构及其适应性研究. 中国沙漠, 25, 249-255.]

Tong QX, Zhang B, Zheng LF (2006). Hyperspectral Remote Sensing. Higher Education Press, Beijing. 246-283. (in Chinese) [童庆禧, 张兵, 郑兰芬 (2006). 高光谱遥感 一原理, 技术与应用. 高等教育出版社, 北京. 246-283.]

Ustin SL, Valko PG, Kefauver SC, Santos MJ, Zimpfer JF, Smith SD (2009). Remote sensing of biological soil crust under simulated climate change manipulations in the Mojave Desert. Remote Sensing of Environment, 113, 317328.

Wang XQ, Zhang YM, Wang YC, Wan JP, Xu M (2006). Eco-environment change of biological crusts on longitudinal dune surface in Gurbantunggut Desert. Journal of Desert Research, 26, 711-716. (in Chinese with English abstract) [王雪芹, 张元明, 王远超, 万金平，徐曼 (2006). 古尔班通古特沙漠生物结皮小尺度分异的环境 特征. 中国沙漠, 26, 711-716.]

Wang XQ, Zhang YM, Zhang WM, Yang DL (2011). The aerodynamic roughness length of biological soil crusts: A case study of Gurbantunggut Desert. Acta Ecologica Sinica, 31, 4153-4160. (in Chinese with English abstract) [王雪芹, 张元明, 张伟民, 杨东亮 (2011). 生物结皮粗 糙特征——古尔班通古特沙漠为例. 生态学报, 31 , 4153-4160.]

Wang Y, Zhao YG, Yao CZ, Zhang PP (2014). Surface roughness characteristics of biological soil crusts and its influencing factors in the Hilly Loess Plateau region, China. Chinese Journal of Applied Ecology, 25, 647-656. (in Chinese with English abstract) [王媛, 赵允格, 姚春竹, 张培培 (2014). 黄土丘陵区生物土壤结皮表面粘度特 征及影响因素. 应用生态学报, 25, 647-656.]

Weber B, Hill J (2016). Remote sensing of biological soil crusts at different scales. In: Weber B, Büdel B, Belnap J eds. Biological Soil Crusts: An Organizing Principle in Drylands. Springer, Cham, Switzerland. 215-232.

Weber B, Olehowski C, Knerr T, Hill J, Deutschewitz K, Wessels DCJ, Eitel B, Büdel B (2008). A new approach for mapping of biological soil crusts in semidesert areas with hyperspectral imagery. Remote Sensing of Environment, 112, 2187-2201.

Wu L (2012). On the Formation Process of Lichen Soil Crust and Their Photosynthetic Physiology. PhD dissertation, Institute of Hydrobiology, Chinese Academy of Sciences, Beijing. 23-38. (in Chinese with English abstract) [吴丽 (2012). 地衣结皮形成的生物学过程及其光合生理研究. 博士学位论文, 中国科学院水生生物研究所, 北京. 23-38.]

Xu J, Bai XL, Tian GQ, Huang J, Zhang D, Feng XH (2005). Ecological function of mosses in biotic crusts on fixed 
dunes on Tengger Desert and its relation with soil factors. Journal of Desert Research, 25, 234-242. (in Chinese with English abstract) [徐杰, 白学良, 田桂泉, 黄洁, 张镝, 冯晓慧 (2005). 腾格里沙漠固定沙丘结皮层藓类植物 的生态功能及与土壤环境因子的关系. 中国沙漠, 25 , 234-242.]

Yao DL, Li JC, Du Y, Li XR, Zhang JG (2002). A land-atmosphere coupling model and mechanism of the crust layer and evolution of canopy in artificial vegetation area of Shapoto. Acta Ecologica Sinica, 22, 452-460. (in Chinese with English abstract) [姚德良, 李家春, 杜岳, 李新荣, 张景光 (2002). 沙坡头人工植被区陆气耦合模 式及生物结皮与植被演变的机理研究. 生态学报, 22 , 452-460.]

Zaady E, Bouskila A (2002). Lizard burrows association with successional stage of biological soil crusts in an arid sandy region. Journal of Arid Environments, 50, 235-246.

Zaady E, Karnieli A, Shachak M (2007). Applying a field spectroscopy technique for assessing successional trends of biological soil crusts in a semi-arid environment. Journal of Arid Environments, 70, 463-477.

Zaady E, Kuhn U, Wilske B, Sandoval-Soto L, Kesselmeier J (2000). Patterns of $\mathrm{CO}_{2}$ exchange in biological soil crusts of successional age. Soil Biology \& Biochemistry, 32, 959966.

Zhang J, Zhang YM (2014). Diurnal variations of chlorophyll fluorescence and $\mathrm{CO}_{2}$ exchange of biological soil crusts in different successional stages in the Gurbantunggut Desert of northwestern China. Ecological Research, 29, 289-298. Zhang YM, Pan HX, Pan BR (2004). Distribution characteris- tics of biological crust on sand dune surface in Gurbantunggut Desert, Xinjiang. Journal of Soil and Water Conservation, 18(4), 61-64. (in Chinese with English abstract) [张元明, 潘惠霞, 潘伯荣 (2004). 古尔班通古特沙漠 不同地貌部位生物结皮的选择性分布. 水土保持学报, 18(4), 61-64.]

Zhao Y, Jia RL, Teng JL, Jia WX, Gao YH (2017). Response of biological soil crust coverage to wind-blown sand burial during the succession of the artificially sand-fixing vegetation in the Tengger Desert, Northern China. Acta Ecologica Sinica, 37, 6138-6148. (in Chinese with English abstract) [赵芸, 贾荣亮, 滕嘉玲, 贾文雄, 高艳红 (2017). 腾格里沙漠人工固沙植被演替生物土壤结皮 盖度对沙埋的响应. 生态学报, 37, 6138-6148.]

Zhao YG, Xu MX, Belnap J (2010). Response of biocrusts' photosynthesis to environmental factors: A possible explanation of the spatial distribution of biocrusts in the Hilly Loess Plateau region of China. Acta Ecologica Sinica, 17, 4668-4675. (in Chinese with English abstract) [赵允格, 许明祥, Jayne Belnap (2010). 生物结皮光合作 用对光温水的响应及其对结皮空间分布格局的解译 —以黄土丘陵区为例. 生态学报, 17, 4668-4675.]

Zhao YS, Chen DM, Yang LM, Zhou XT, Li XM, Tang WZ (2003). Principle and Method of Analysis of Remote Sensing Application. Science Press, Beijing. 366-409. (in Chinese) [赵英时, 陈冬梅, 杨立明, 周心铁, 李小文, 唐文 周 (2003). 遥感应用分析原理与方法. 科学出版社, 北 京. 366-409.]

特邀编委: 刘华杰 责任编辑: 王 藏

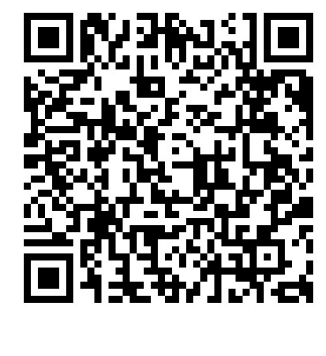

www.plant-ecology.com 